\title{
The cariogenic dental biofilm: good, bad or just something to control?s
}

\section{Mark Steven Wolff(a) Charlie Larson ${ }^{(b)}$}

(a) $\mathrm{PhD}$, Professor; (b) MSc, Assistant Professor - Department of Cariology and Comprehensive Care, New York University College of Dentistry, New York, NY, USA.
\$Paper presented at the "Oral Health Self-Care Products: Realities and Myths" international symposium, sponsored by the Brazilian Association for Oral Health Promotion (ABOPREV), September 25-27, 2008, São Paulo, SP, Brazil.

Corresponding author:

Mark Steven Wolff

Department of Cariology and

Comprehensive Care

New York University College of Dentistry

345 East $24^{\text {th }}$ Street (MC9480)

New York, NY 10010 U.S.A.

E-mail: mark.wolff@nyu.edu

Received for publication on Feb 23, 2009

Accepted for publication on May 11, 2009

\begin{abstract}
This paper discusses the role of dental biofilm and adjunctive therapies in the management of dental caries. Dental biofilm is a site of bacterial proliferation and growth, in addition to being a location of acid production. It also serves as a reservoir for calcium exchange between the tooth and saliva. The salivary pellicle, a protein-rich biofilm layer, regulates the reaction between tooth surface, saliva and erosive acids. The protective effects of this pellicle on enamel are well established. However, understanding the effects of the pellicle/biofilm interaction in protecting dentin from erosive conditions requires further research. Saliva interacts with the biofilm, and is important in reducing the cariogenic effects of dental plaque as acidogenic bacteria consume fermentable carbohydrates producing acids that may result in tooth demineralization. Adequate supplies of healthy saliva can provide ingredients for successful remineralization. Strategies for managing the cariogenic biofilm are discussed with emphasis on the effectiveness of over-the-counter (OTC) products. However, since many toothpaste components have been altered recently, new clinical trials may be required for true validation of product effectiveness. A new generation of calcium-based remineralizing technologies may offer the ability to reverse the effects of demineralization. Nevertheless, remineralization is a microscopic subsurface phenomenon, and it will not macroscopically replace tooth structure lost in a cavitated lesion. Optimal management of cavitations requires early detection. This, coupled with advances in adhesive restorative materials and microsurgical technique, will allow the tooth to be restored with minimal destruction to nearby healthy tissue.
\end{abstract}

Descriptors: Dental plaque; Tooth remineralization. 


\section{Introduction}

The role of the dental biofilm has long been implicated in the development of caries. Miller ${ }^{1}$ (1890) proposed a two step process whereby mixed bacteria, when exposed to fermentable carbohydrates, produced acids which, in a second step, acted on tooth structure to dissolve hydroxyapatite and release free calcium and phosphates. Plaque accumulation, subsequent production of acids within the plaque in response to a glucose exposure and subsequent recovery of the plaque $\mathrm{pH}$ was demonstrated by Stephan $(1940,1944){ }^{2,3}$ The introduction of dietary carbohydrates, even in thin layers of plaque, resulted in significant production of acid. The extent of the $\mathrm{pH}$ drop and the longevity of that drop are heavily regulated by saliva and salivary components. ${ }^{2-5}$ This process of acid production is widely accepted in the demineralization of tooth structure (enamel and dentin) and the subsequent development of caries-generated tooth cavitation.

Dental plaque is a diverse community found on the tooth surface embedded in a matrix of polymers of bacterial and salivary origin. ${ }^{6}$ Marsh, Bradshaw ${ }^{7}$ (1995) describes the process of developing a mature biofilm as:

1. The formation of a conditioning film (acquired pellicle) on the tooth surface;

2. the interaction between salivary bacteria and the acquired pellicle (non-specific, followed by primary colonizers);

3. the attachment of secondary colonizers to the primary colonizers;

4. the development of horizontal and vertical stratification;

5. the growth and formation of a climax community.

Kleinberg $^{8}$ (1987) demonstrated in vivo that the formation of bacterial plaque actually starts at a considerably more mature phase than described above. He demonstrated that the very minor hardto-clean surface defects on the tooth actually serve as the starting points for the repopulation of the tooth with a mature plaque. A plaque initially infected with Streptococcus mutans (only one of the bacteria capable of generating an acidic shift in the biofilm) in an infant or young child ${ }^{9}$ may be shifted to one that is primarily acid-tolerant simply by the ongoing exposure to the acid environment. ${ }^{10}$ The oral bacteria present in the biofilm, if acidogenic in nature, clearly have the ability to generate the acids needed to demineralize tooth structure in response to a fermentable carbohydrate challenge. If allowed to mature even for short periods of time, the biofilm develops the ability to sustain this acid generation.

The biofilm, related to dental caries, functions in several ways. It is a site of bacterial proliferation and growth, as described above, a location of acid/ base regulation at the tooth surface, and a reservoir for calcium ion exchange between the tooth and the saliva.

Hannig et al. ${ }^{11}$ (2003) demonstrated that pellicle formation, even as early as 2 hours, imparts significant resistance to enamel demineralization. In earlier studies specifically designed to investigate pellicle, not plaque, Hannig, Balz ${ }^{12}$ (1999) demonstrated that a pellicle less than 24 hours in age demonstrated marked protective qualities on enamel when challenged by erosive acids. They also noted that short term exposure to phosphoric or citric acid could completely remove the protective pellicle. Later on, Hannig et al. ${ }^{11}$ (2003) demonstrated that a salivary pellicle only 3 minutes old conferred protection to enamel against citric acid attack. They demonstrated that the pellicle is $20-500 \mathrm{~nm}$ thick within the first two hours of exposure to saliva, depending on location, and is resistant to removal by a toothbrush (without toothpaste) and masticatory forces. The protein-rich biofilm layer, salivary pellicle, is the interface that regulates the reaction between tooth surface, saliva and erosive acids. The protective effects of the pellicle on enamel appear to be well established by multiple research groups. Unfortunately the effects of the pellicle on dentin have had only limited research. Hara et al. ${ }^{13}$ (2006) demonstrated that a two-hour pellicle offered little resistance to erosive challenge on dentin. They asserted that the lower protective quality of pellicle on dentin may be due to the fact that a) dentin is more soluble than enamel and b) the pellicle could not resist the acid attack. It was speculated that greater protection of dentin could be expected if the pellicle was allowed to mature for more than two hours. The pellicle/ 
biofilm interaction in protecting dentin from erosive challenges requires further investigation. The ability of the biofilm to neutralize acid attack as well as to initiate and support remineralization of the dentin surface appears to be a critical step in determining if it demineralizes.

The effects of saliva on the risk of developing dental caries are dramatic when there is significant loss of secretion resulting from development of xerostomia, either by disease, radiation therapy or use of any of nearly 1,000 drugs that have hyposalivation side effects. ${ }^{14}$ Saliva is critical to the protection of the teeth against the acidic $\mathrm{pH}$ changes that result in dental plaque when its bacteria degrade fermentable carbohydrates. ${ }^{2}$ Adequate amounts of healthy saliva supply all the necessary ingredients for successful remineralization, and the lack of it severely handicaps the natural repair process. Bicarbonate, phosphate, urea, amino acids and peptides collectively work to buffer or neutralize the $\mathrm{pH}$ of the plaque present on teeth. ${ }^{15}$ In some instances, salivary amino acids and peptides containing arginine are utilized to raise the $\mathrm{pH}$ of dental plaque ${ }^{16}$ by favoring the growth of base forming bacteria. The flow, distribution throughout the mouth and the general dilution properties of saliva also act to cleanse the mouth of adherent food, bacteria and their nutrients. The rapid clearance of carbohydrates protects against caries lesion development. Furthermore, the calcium and phosphate ions in saliva protect the teeth from acid dissolution and help with remineralization as well, when this occurs. ${ }^{17}$

In 1944, Stephan carried out a classic study in which he showed that the $\mathrm{pH}$ fall in response to a standard sugar rinse was lower in caries active individuals than in those in whom caries activity was less or zero. Multiple studies in animals, humans and model systems have demonstrated that saliva plays a major role in dental caries prevention. ${ }^{18,19}$

\section{The plaque, saliva and tooth chemistry of demineralization and remineralization}

Stephan (1944) suggested a critical pH for enamel, below which the enamel would dissolve. There needs to be sufficient acid production to develop a plaque that is undersaturated with respect to calcium and phosphates. Saliva provides calcium and phosphate that help prevent the dissolution of tooth enamel in the form of calcium and phosphate ions as well as a calcium phosphate carbohydrate protein complex named salivary precipitin. ${ }^{20}$ The presence of these calcium and phosphate complexes prevents the dissolution of enamel in mildly acidic environments. In fact, in neutral to slightly basic environments these calcium and phosphate complexes may actually push calcium into the tooth surface (or precipitate in the form of calculus) (Figure 1). At the enamel surface, small chain acids produced by bacteria (e.g. formic, lactic, acetic, and propionic acids) enter the porous enamel via small diffusion channels that allow tiny molecules and ions to diffuse into the subsurface, demineralizing the surface. ${ }^{22}$ Solubilized calcium and phosphate move to the tooth surface in response to the acid challenge and concentration gradient. As long as the tooth surface is in an acid environment that is undersaturated with respect to calcium and phosphate, the tooth will dissolve. The demineralization at the tooth surface layer is reduced because of the accumulation of calcium and phosphate ions at the tooth surface both from plaque, as described above, and from the tooth structure below. This results in surface stability or remineralization as the tooth is buffered to neutrality. In cariogenic conditions such as ongoing exposure to fermentable carbohydrates, acid production continues and acid diffuses into an ever increasingly accessible enamel subsurface resulting in the demineralizing of enamel crystals and the release of carbonate, calcium, phosphate, etc into the biofilm and eventually into the saliva, resulting in a loss of mineral from the tooth. The acid $\mathrm{pH}$ generated by the microbial metabolism is neutralized by saliva in several ways. In the simplest form, saliva dilutes and washes the acids away (though this may also act to remove mineralized material). Saliva contains bicarbonate which can directly buffer the acids. Another mechanism of neutralizing acids is present. As the plaque is a mixed culture containing many bacteria, an increased amount of saliva serves to bring the plaque other nutrients such as the amino acid arginine and urea. Both of these compounds serve 
Figure 1 - The movement of calcium and phosphate into and out of the biofilm in response to acid conditions determines whether the tooth demineralizes or remineralizes.

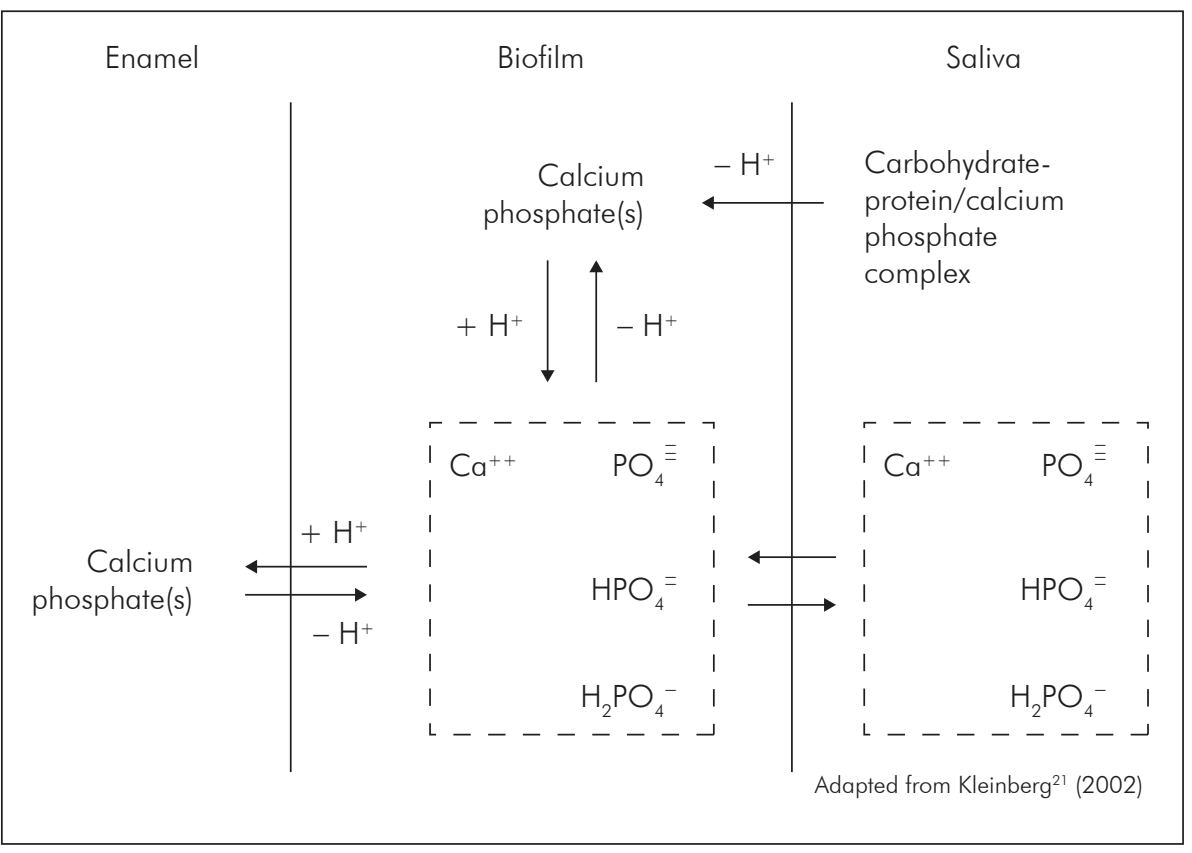

as substrates for bacteria that create base as a metabolic byproduct. The biofilm is rich in arginolytic bacteria that produce base in response to the exposure to saliva, helping neutralize the acid produced.

It is noteworthy that if the enamel surface remains intact, bacteria have no way of invading the dentin because these enamel diffusion channels are very small, making it impossible for the much larger bacteria to diffuse into the tooth (even though a radiograph may reveal significant enamel density loss). Thus, chemical remineralization therapies rather than surgical intervention are indicated when there is an intact enamel surface. ${ }^{23}$ In addition, evidence suggests that these non-cavitated lesions can also be managed in occlusal surfaces by sealing them from the environment. ${ }^{24,25}$ Once the surface is significantly cavitated, it is no longer practical to rely on remineralization as a viable clinical treatment option. Remineralization is a microscopic subsurface phenomenon and will not macroscopically replace the tooth structure of a cavitation. At this point, surgical restoration is indicated. Careful early detection of cavitations can result in less invasive surgicalmechanical treatments. Thus, if restoration is necessary, such early detection coupled with advances in adhesive restorative materials and microsurgical technique will allow the tooth to be restored with minimal destruction to nearby hard tissue that is still healthy. ${ }^{26}$

\section{Strategies for managing a cariogenic biofilm}

The management of a cariogenic biofilm may be looked at in several ways. Three strategies have dominated the history of modern dentistry: a) Plaque elimination/reduction by home care, b) fermentable carbohydrate reduction or elimination and c) introduction of fluoride to reduce caries. Combinations of these strategies have been responsible for substantial reductions in dental caries rates, but not for the elimination of caries. Oral hygiene education has been demonstrated to reduce bacterial counts, but not reduce the bacterial burden by clinically significant amounts. ${ }^{27}$ Plaque elimination by tooth brushing has been well documented. The question arises as to whether powered tooth brushing reduces plaque more than manual tooth brushing. When evaluating the effectiveness of homecare programs several strategies must be discussed. The two most common homecare strategies are brushing and flossing. The use of the toothbrush is clearly effective at removing plaque, but studies comparing powered and manual toothbrushes fail to show significant clinical differences. A Cochrane review found that 
only small improvements were found in plaque accumulation with oscillating powered brushes over manual brushes. ${ }^{28}$ No conclusions were made related to their effectiveness related to the management of dental caries. A review of the literature related to flossing and dental caries revealed that self-flossing failed to reveal effectiveness in caries reduction. ${ }^{29} \mathrm{It}$ must be remembered that when reviewing studies related to tooth brushing effectiveness and caries, it is difficult to separate out the effect of multiple tooth brushings with fluoride toothpastes which have been demonstrated to reduce caries rates.

The effectiveness of over-the-counter toothpastes is without question. The incremental reduction in caries is increased both with the concentration of fluoride in the toothpaste, the frequency of use and the baseline caries rates in the patients when toothpaste is introduced. ${ }^{30}$ These products have undergone major clinical evaluation in the past, but in recent history, many of the toothpaste components have been altered. Though many laboratory studies have been performed on the products, the addition of new components should raise concerns that new clinical trials are required to allow continued validation of the products' effectiveness. Adjunctive fluoride therapy in the presence of fluoride toothpaste has demonstrated effectiveness, though only by a small increment. ${ }^{31}$

\section{Anti-microbial therapies}

The concept of reducing plaque utilizing antimicrobial agents seems like a reasonable strategy. Stannous fluoride and amine fluoride as well as numerous metallic ions have demonstrated antimicrobial effectiveness. ${ }^{32,33}$ Tin, zinc, copper and others have demonstrated anti-microbial effects, but none have demonstrated anti-caries effectiveness. Essential oils, a mixture of thymol, eucalyptol, methyl salicylate and menthol have been demonstrated to be effective in preventing the build-up of supra-gingival plaque and gingivitis, ${ }^{34,35}$ but have not demonstrated effectiveness in the reduction of caries lesions. Triclosan has also demonstrated effectiveness in reducing plaque and gingivitis, but has also failed to produce reductions in caries. ${ }^{36}$ Chlorhexidine, a bisguanide, is a broad spectrum antimicrobial that functions by disturbing the cell membrane of bacteria. Studies have demonstrated that chlorhexidine, administered frequently enough and in high enough doses, can reduce the Streptococcus mutans bioburden in the mouth. ${ }^{37}$ Unfortunately, clinical studies focusing on actual caries reductions have been equivocal.

\section{Calcium based remineralizing therapeutic approaches}

Remineralization of the tooth is not a new concept. Calcium products have been recommended for decades with in vitro data demonstrating constriction of exposed tubules when treated with $\mathrm{Ca}(\mathrm{OH})_{2} \cdot{ }^{38}$ The problem with surface application of $\mathrm{Ca}(\mathrm{OH})_{2}$ was its ease of solubility in the oral environment. Since that time, multiple calcium based desensitizing solutions have emerged. In the early 1990's an amorphous calcium phosphate (ACP) based product became commercially available. The dentifrice contained sodium fluoride, calcium salts and phosphate salts (calcium separated from the phosphate and fluoride by a plastic divider in the tube to prevent interaction). In an eight week clinical trial, the product was shown to reduce sensitivity equivalent to any of the medicinal based products available at the time. ${ }^{39}$ The ACP technology has recently been incorporated in a commercially available sodium bicarbonate containing toothpaste, prophylaxis pastes and varnish products.

In the late 90's, a new calcium based remineralizing product was introduced demonstrating successful desensitization both as a toothpaste and as a prophylaxis paste. This product is an arginine bicarbonate/calcium carbonate compound (Cavistat $^{\mathrm{TM}}$, Ortek Therapeutics, Garden City, NY, USA) that can be incorporated into multiple delivery platforms to assist in mineralization. Its mechanism of action has been described as follows: "The highly soluble arginine bicarbonate component surrounds, or is surrounded by, particles of poorly soluble calcium carbonate component, and because of the adhesive qualities of this composition, forms a paste-like plug that not only fills but also adheres to the dentinal tubule walls. Because of its alkalinity, the arginine bicarbonate/calcium carbonate also reacts with the 
calcium and phosphate ions of the dentinal fluid to make the plug chemically contiguous with the dentinal walls...." ${ }^{40}$ The clinical longevity of this obturation was demonstrated in a clinical trial after a single prophylaxis treatment with a paste containing arginine bicarbonate/calcium carbonate. Sixty percent of the teeth remained totally asymptomatic to air and $77.4 \%$, totally asymptomatic to scratch. Of the teeth not rendered totally asymptomatic with the single treatment, most experienced marked improvement in symptoms. ${ }^{41}$ Clinical trials involving the twice-daily self-application of the toothpaste containing arginine bicarbonate/calcium carbonate achieved similar results. These same products are being utilized in anti-caries products. Two recent studies, one double-blind placebo controlled study utilizing a chewable mint and the other, a cohortcontrolled study of a Cavistat ${ }^{\mathrm{TM}}$ containing toothpaste, demonstrated reduction in new decayed, missing or filled surfaces (DMFS) as well as reversals of early lesions. ${ }^{42,43}$

Again, in the late 90's, another calcium based remineralizing technology became available. This product addressed the delivery system problem of stabilizing amorphous calcium phosphate under neutral or alkaline conditions increasing the plaque's content of calcium and phosphate ${ }^{44}$ by the incorporation of a casein phospho-peptide with amorphous

\section{References}

1. Miller WD. The microorganisms of the human mouth: the local and general diseases which are caused by them. Basel; New York: S. Karger; 1973. Reprint of the 1890 ed. published by The S. S. White Dental Mfg. Co., Philadelphia.

2. Stephan RM. Changes in hydrogen ion concentration on tooth surfaces and in carious lesions. J Am Dent Assoc. 1940;27:71823.

3. Stephan RM. Intra-oral hydrogen ion concentrations associated with dental caries activity. J Dent Res. 1944;23:257-66.

4. Kleinberg I. Formation and accumulation of acid on the tooth surface. J Dent Res. 1970;49(6):1300-17.

5. Kleinberg I, Jenkins GN, Chatterjee R, Wijeyeweera L. The antimony $\mathrm{pH}$ electrode and its role in the assessment and interpretation of dental plaque pH. J Dent Res. 1982;61(10):113947.

6. Marsh P, Martin M. Oral Microbiology. $3^{\text {rd }}$ ed. London: Chapman and Hall; 1992. calcium phosphate (CPP-ACP). This product, in a series of in situ studies, has demonstrated the ability to remineralize enamel that was previously demineralized. ${ }^{45}$ The effectiveness of the CPP-ACP product in reducing dentin hypersensitivity was demonstrated utilizing a toothpaste delivery system. ${ }^{46} \mathrm{~A}$ recent double-blind clinical study investigated, using digital bitewing radiography, the progression and regression of approximal caries in 2,720 adolescent subjects chewing a sugar-free gum containing CPP-ACP over a 24-month study period. Caries progression or regression was analyzed, and for subjects chewing the CPP-ACP gum the odds of a surface experiencing caries progression were $18 \%$ less. $^{47}$

\section{Conclusions}

The principles of caries risk assessment should be applied to all patients. Adjunctive anti-caries agents should be recommended commensurate with the caries risk. Home care, fluoride toothpaste and fermentable carbohydrate reduction have been the mainstays of clinical practice for the better part of the last half century. Despite these recommendations, wide spread public fluoridation and improved dental care, dental caries remains a pandemic condition. Adjunctive therapies are necessary and even greater research must be done on these products.

7. Marsh PD, Bradshaw DJ. Dental plaque as a biofilm. J Ind Microbiol. 1995;15(3):169-75

8. Kleinberg I. Salivary control of the composition and metabolism of dental plaque. In: Sreebny L, editor. The salivary system. Boca Raton: CRC Press; 1987. p. 203-23.

9. Caufield PW, Li Y, Dasanayake A. Dental caries: an infectious and transmissible disease. Compend Contin Educ Dent. 2005;26(5 Suppl 1):10-6.

10. Bradshaw DJ, McKee AS, Marsh PD. Effects of carbohydrate pulses and $\mathrm{pH}$ on population shifts within oral microbial communities in vitro. J Dent Res. 1989;68(9):1298-302.

11. Hannig M, Hess NJ, Hoth-Hannig W, De Vrese M. Influence of salivary pellicle formation time on enamel demineralization - an in situ pilot study. Clin Oral Investig. 2003;7(3):15861.

12. Hannig M, Balz M. Influence of in vivo formed salivary pellicle on enamel erosion. Caries Res. 1999;33(5):372-9. 
13. Hara AT, Ando M, Gonzalez-Cabezas C, Cury JA, Serra MC, Zero DT. Protective effect of the dental pellicle against erosive challenges in situ. J Dent Res. 2006;85(7):612-6.

14. Sreebny LM, Schwartz SS. A reference guide to drugs and dry mouth $-2^{\text {nd }}$ edition. Gerodontology. 1997;14(1):33-47.

15. Mandel ID. The functions of saliva. J Dent Res. 1987;66 Spec No:623-7.

16. Kleinberg I, Kanapka J, Chatterjee R, Craw D, D’Angelo NK, Sandham HG. Metabolism of nitrogen by the oral mixed bacteria. In: Saliva and dental caries. Kleinberg I, Ellison SA, Mandel ID, editors. Washington, DC, and London: Information Retrieval; 1979. p. 357-77.

17. Kleinberg I, Chatterjee R, Denepetya L. Effects of saliva and dietary eating habits on the $\mathrm{pH}$ and demineralisation-remineralisation potential of dental plaque. DemineralisationRemineralisation of the Teeth. Oxford: IRL Press; 1983. p. 25-50.

18. Britse A, Lagerlof $F$. The diluting effect of saliva on the sucrose concentration in different parts of the human mouth after a mouth-rinse with sucrose. Arch Oral Biol. 1987;32(10):7556.

19. Lindfors B, Lagerlö F. Effect of sucrose concentration in saliva after sucrose rinse on the hydronium ion concentration in dental plaque. Caries Res. 1988;22:7-10.

20. Kleinberg I, Kaufman HW, Wolff M. Measurement of tooth hypersensitivity and oral factors involved in its development. Arch Oral Biol. 1994;39 Suppl:63S-71S.

21. Kleinberg I. A mixed-bacteria ecological approach to understanding the role of the oral bacteria in dental caries causation: an alternative to Streptococcus mutans and the specific-plaque hypothesis. Crit Rev Oral Biol Med. 2002;13(2):108-25.

22. Featherstone JD, Holmen L, Thylstrup A, Fredebo L, Shariati M. Chemical and histological changes during development of artificial caries. Caries Res. 1985;19(1):1-10.

23. Featherstone JD, Cutress TW, Rodgers BE, Dennison PJ. Remineralization of artificial caries-like lesions in vivo by a self-administered mouthrinse or paste. Caries Res. 1982;16(3):235-42.

24. Griffin SO, Oong E, Kohn W, Vidakovic B, Gooch BF, Bader J et al. The effectiveness of sealants in managing caries lesions. J Dent Res. 2008;87(2):169-74.

25. Oong EM, Griffin SO, Kohn WG, Gooch BF, Caufield PW. The effect of dental sealants on bacteria levels in caries lesions: a review of the evidence. J Am Dent Assoc. 2008;139(3):271-8; quiz 357-8.

26. Fontana MR, Young DA, Wolff MS. Evidence Based Caries Risk Assessment and Treatment; In Press.

27. Smiech-Slomkowska G, Jablonska-Zrobek J. The effect of oral health education on dental plaque development and the level of caries-related Streptococcus mutans and Lactobacillus spp. Eur J Orthod. 2007;29(2):157-60.

28. Heanue M, Deacon SA, Deery C, Robinson PG, Walmsley AD, Worthington HV et al. Manual versus powered toothbrush- ing for oral health. Cochrane Database Syst Rev 2003;(1): CD002281. Review. Update in: Cochrane Database Syst Rev. 2005;(2):CD002281.

29. Hujoel PP, Cunha-Cruz J, Banting DW, Loesche WJ. Dental flossing and interproximal caries: a systematic review. J Dent Res. 2006;85(4):298-305.

30. Marinho VC, Higgins JP, Sheiham A, Logan S. Fluoride toothpastes for preventing dental caries in children and adolescents. Cochrane Database Syst Rev. 2003;(1):CD002278. Review.

31. Marinho VC. Evidence-based effectiveness of topical fluorides. Adv Dent Res. 2008;20(1):3-7.

32. Gaffar A, Afflitto J, Nabi N. Chemical agents for the control of plaque and plaque microflora: an overview. Eur J Oral Sci. 1997;105(5 Pt 2):502-7.

33. Scheie AA, Fejerskov O, Assev S, Rolla G. Ultrastructural changes in Streptococcus sobrinus induced by xylitol, $\mathrm{NaF}$ and $\mathrm{ZnCl}_{2}$. Caries Res. 1989;23(5):320-7.

34. Charles CH, Vincent JW, Borycheski L, Amatnieks Y, Sarina M, Qaqish J et al. Effect of an essential oil-containing dentifrice on dental plaque microbial composition. Am J Dent. 2000;13(Spec No):26C-30C.

35. Walker CB. Microbiological effects of mouthrinses containing antimicrobials. J Clin Periodontol. 1988;15(8):499-505.

36. Gjermo P, Saxton CA. Antibacterial dentifrices. Clinical data and relevance with emphasis on zinc/triclosan. J Clin Periodontol. 1991;18(6):468-73.

37. Ribeiro LG, Hashizume LN, Maltz M. The effect of different formulations of chlorhexidine in reducing levels of mutans streptococci in the oral cavity: A systematic review of the literature. J Dent. 2007;35(5):359-70.

38. Brannstrom M, Isacsson G, Johnson G. The effect of calcium hydroxide and fluorides on human dentine. Acta Odontol Scand. 1976;34(2):59-67.

39. Kaufman HW, Wolff MS, Winston AE, Triol CW. Clinical evaluation of the effect of a remineralizing toothpaste on dentinal sensitivity. J Clin Dent. 1999;10(1 Spec No):50-4.

40. Kleinberg I. SensiStat. A new saliva-based composition for simple and effective treatment of dentinal sensitivity pain. Dent Today. 2002;21(12):42-7.

41. Wolff MS, Kleinberg I. Duration of reduction of dentinal hypersensitivity after prophylaxis with calcium/arginine bicarbonate carbonate paste. J Dent Res. 2003;82(Abstract):180.

42. Acevedo AM, Machado C, Rivera LE, Wolff M, Kleinberg I. The inhibitory effect of an arginine bicarbonate/calcium carbonate CaviStat-containing dentifrice on the development of dental caries in Venezuelan school children. J Clin Dent. 2005;16(3):63-70.

43. Acevedo AM, Montero M, Rojas-Sanchez F, Machado C, Rivera LE, Wolff $\mathrm{M}$ et al. Clinical evaluation of the ability of CaviStat in a mint confection to inhibit the development of dental caries in children. J Clin Dent. 2008;19(1):1-8. 
- The cariogenic dental biofilm: good, bad or just something to control?

44. Reynolds EC. Anticariogenic complexes of amorphous calcium phosphate stabilized by casein phosphopeptides: a review. Spec Care Dentist. 1998;18(1):8-16.

45. Shen P, Cai F, Nowicki A, Vincent J, Reynolds EC. Remineralization of enamel subsurface lesions by sugar-free chewing gum containing casein phosphopeptide-amorphous calcium phosphate. J Dent Res. 2001;80(12):2066-70.
46. Walsh LJ, Wong WS, Cakar A, Devani G, Tran KK, Hall A. Effect of CPP-ACP versus potassium nitrate on cervical dentinal hypersensitivity. J Dent Res. 2006(Abstract):947.

47. Morgan MV, Adams GG, Bailey DL, Tsao CE, Fischman SL, Reynolds EC. The anticariogenic effect of sugar-free gum containing CPP-ACP nanocomplexes on approximal caries determined using digital bitewing radiography. Caries Res. 2008;42(3):171-84. 